\title{
Simulation in Single and Multi-Flow Direction of Airflow Sensor
}

\author{
Sukarnur Che Abdullah ${ }^{1 *}$, Mohamad Dzulhelmy bin Amari ${ }^{2,}$ Amirul Shafiq bin Abdullah Sabil ${ }^{3}$ \\ ${ }^{12}$ Faculty of Mechanical Engineering, University Technology MARA (UiTM), 40150, Shah Alam, Selangor, Malaysia. \\ ${ }^{3}$ School of Engineering, KDU University College,40150, Shah Alam, Selangor, Malaysia. \\ *Corresponding author E-mail: sukarnur.ca@gmail.com
}

\begin{abstract}
This paper investigates simulation of air flow acting on the airflow sensor using the Computational Fluid Dynamic (CFD) approach. Simulation is carried out to evaluate the performance of airflow sensor by analysing small change of the air flow acting on the airflow sensor structure. Identification of the characteristics and parameters for the sensor in motion was done to achieve higher accuracy of the airflow result. Analyzation stage from the obtained data comprehending the behaviour of the airflow in higher accuracy while sensor in motion will be verified by detection of high sensitivity in relative velocity of the airflow sensor compared to conventional sensor. Therefore, an analysis was conducted with three different airflow directions involving necessary boundary condition and parameter. The efficiency from the tabulated data for dynamic motion has also been determined by comparing simulation data with calculation. All simulations and analyses were completed using the ANSYS software.
\end{abstract}

Keywords: Airflow sensor, Relative velocity, Single direction, Multi-flow direction.

\section{Introduction}

Innovations result in advanced sensor development which give a huge impact on our daily life. One of the most crucial elements which assists people to communicate with the environment is the sensor. Change of the airflow movement from the surroundings can be detected by the model sensor which has the capability in detecting small changes of airflow motion with high accuracy.

The scope of this study is to focus on evaluating the performance of airflow by determining the little changes of air flow through the airflow sensor based on necessary boundary condition and parameter for low velocity range. Previous papers have shown that usage of Acrylonitrile butadiene styrene (ABS) materials produce different effect towards the performance and detection range for the airflow sensor [1]. The difference in the structure may reflect the performance of the airflow model where some of the sensors use the concept of small insects' detection structure [2]. These criteria are imperative for the air sensor to work in high sensitivity.

This study also focusses on improvising technology in terms of sensing relative motion. The airflow sensor was designed to cover the airspeed between 0 to $110 \mathrm{~km} / \mathrm{h}$ with high accuracy. The airflow sensor is particularly created for specific functions and is generally ready to measure the airflow in static position [3-4]. This obstruction needs to be overcome to produce better airflow sensor. To counter that, this paper also focusses on finding the dynamic motion parameter of the airflow sensor. Simulation in multi-flow direction will be made to achieve this objective. The study will focus more on multiple airflow detection towards the changes of surrounding air movement. Hence, this type of airflow sensor can give huge impact in the future.

\section{Methodology}

\subsection{Design Prototype Model}

Generally, design have been optimized by using the method described by N. Svedin [5] . In this case, the thermal approach is not excessively compelling all together, making it impossible to outline the high sensitivity of airflow sensor because of the external condition that influences the execution of the sensor especially the weather.Design have been make by using Solidwork software. The air sensor design schematically shown in Figure 1 and Figure 2. The model airflow sensor is designed to be as modular type in order the capability and flexibility to be installed in any moving application. The general dimension size to comprehend with the criteria where the diameter of the casing is $7 \mathrm{~cm}$ and the height of the casing will be $3.2 \mathrm{~cm}$.

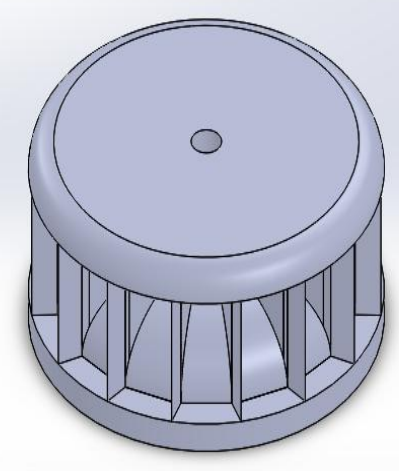

Fig. 1: Overall design of airflow sensor Copyright $\odot 2018$ Authors. This is an open access article distributed under the Creative Commons Attribution License, which permits unrestricted use, distribution, and reproduction in any medium, provided the original work is properly cited. 


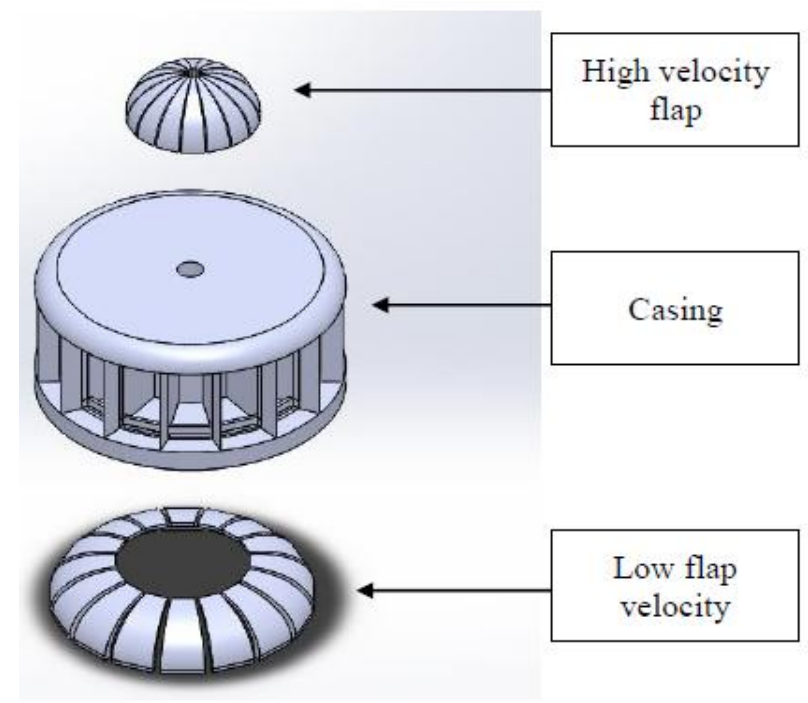

Fig. 2: Design of airflow sensor in extrude view

The design consists of 3 main components which are casing, high velocity flap and low velocity flap. The idea of the flap structure is based on Multi-electrode Metal-core Piezoelectric Fiber (MMPF) [6-7]. A casing is planned as an external cover for the sensor. For smooth airflow movement, a hole has been created at the top of the casing. Low and high velocity flap is designed in the chassis for detecting specific range of low and high velocity respectively. Both components consist of 16 number of entrances around the casing for detection of $360^{\circ}$ air movement. The material used as the sensor element is PLA plastic (Polyactide).

\subsection{Computational Fluid Dynamic Analysis in One Di- rection}

In order to achieve the objective, Computational fluid dynamics (CFD) approach is used. There are three analyses with different number of directions to differentiate the behaviour of the airflow. Design prototype from the applicable computer aided design software is necessary to analysis the software for this purpose After the prototype model is transferred into the analysis software, meshing process will be carried out and all the necessary boundary conditions will be stated. In this case, one direction of airflow will be used to observe behaviour and small change of air flow moving toward the air sensor in low velocity region [8]. Table 1 shows all boundaries condition for this analysis. Simulation is made by using velocity-inlet and laminar flow for viscous model. Velocity magnitude is set at $1.5 \mathrm{~m} / \mathrm{s}$ for this case. The fluid used in this simulation is air which been to the density and viscosity of 1.225 $\mathrm{kg} / \mathrm{m}^{3}$ ]and $1.789 \mathrm{e}-5$ Pa.s respectively.

Table 1: Boundary condition for one direction of velocity

\begin{tabular}{|c|c|c|c|}
\hline \multirow{3}{*}{ Input } & \multicolumn{2}{|c|}{ Type } & Velocity-inlet \\
\hline & \multicolumn{2}{|c|}{ Viscous Model } & Laminar \\
\hline & \multicolumn{2}{|c|}{ Velocity magnitude $(\mathrm{m} / \mathrm{s}-1)$} & 1.5 \\
\hline Output & \multicolumn{2}{|c|}{ Pressure-outlet } & Zero pressure \\
\hline \multirow{2}{*}{$\begin{array}{l}\text { Material- } \\
\text { Fluid }\end{array}$} & \multirow{2}{*}{ air } & Density $\left[\mathrm{kg} / \mathrm{m}^{3}\right]$ & 1.225 \\
\hline & & Viscosity [Pa.s] & $1.789 \mathrm{e}-5$ \\
\hline
\end{tabular}

\subsection{Computational Fluid Dynamics(CFD) Simulation in two (2) Directions}

In this case, two directions of airflow will be acting on the simulation model. Analysis will be done by considering relative motion where a sensor will be connected to a speedometer in the car by substracting with the natural airflow velocity. Resultant velocity from the two directions of airflow acting into the entrance of the air sensor can then be determined. Hence, relative velocity for this CFD model may be studied. To set up the boundary condition, velocity-inlet and laminar flow is used for viscous model. Simulation is made by using velocity-inlet type and laminar flow for viscous model. Axis of the airflow direction is set at $\mathrm{x}$-direction and -x-direction for these two velocity. Pressureoutlet type is used for output at zero pressure Density and viscosity is used at $1.225 \mathrm{~kg} / \mathrm{m}^{3}$ and $1.789 \mathrm{e}-5$ Pa.s respectively which represent air for fluid in this simulation.

Table 2: Boundary condition for two direction of velocity

\begin{tabular}{|l|l|l|l|}
\hline \multirow{2}{*}{ Input } & \multicolumn{2}{|c|}{ Type } & Velocity-inlet \\
\cline { 2 - 4 } & \multicolumn{2}{|c|}{ Viscous Model } & Laminar \\
\cline { 2 - 4 } & Velocity 1 & Incoming air & x-direction \\
\cline { 2 - 4 } & Velocity 2 & $\begin{array}{c}\text { Incoming air } \\
+ \text { Speedometer }\end{array}$ & -x-direction \\
\hline Output & \multicolumn{2}{|c|}{ Pressure-outlet } & Zero pressure \\
\hline $\begin{array}{l}\text { Material- } \\
\text { Fluid }\end{array}$ & \multirow{2}{*}{ air } & Density [ kg/m $\left.{ }^{3}\right]$ & 1.225 \\
\cline { 2 - 4 } & Viscosity [Pa.s] & $1.789 \mathrm{e}-5$ \\
\hline
\end{tabular}

\subsection{Computational Fluid Dynamics(CFD) Simulation in Three Directions}

Simulation in three directions will proceed after simulation in two directions has been achieved. In this simulation, three directions of airflow will be acting on the simulation model with specific axis. Analysis will also be done by considering the relative motion where a sensor will be connected to the speedometer of the car by substracting with the natural airflow velocity. Table 3 shows all the boundaries condition in this case. Simulation is made also by using velocity-inlet and laminar flow for viscous model. Axis of the airflow direction is set at $\mathrm{x}$-direction, - $\mathrm{x}$-direction and $\mathrm{z}$ direction for these three velocity. Pressure-outlet type is used for output at zero pressure. The fluid used in this simulation is air which been set to a density and viscosity at $1.225 \mathrm{~kg} / \mathrm{m}^{3}$ and $1.789 \mathrm{e}-5 \mathrm{~Pa}$.s respectively.

Table 3: Boundary condition for three direction of velocity

\begin{tabular}{|c|c|c|c|}
\hline \multirow{5}{*}{ Input } & \multicolumn{2}{|l|}{ Type } & Velocity-inlet \\
\hline & \multicolumn{2}{|c|}{ Viscous Model } & Laminar \\
\hline & Velocity 1 & Air & $\mathrm{x}$-direction \\
\hline & Velocity 2 & Air+Speedometer & -x-direction \\
\hline & Velocity 3 & Air & Z-direction \\
\hline Output & \multicolumn{2}{|c|}{ Pressure-outlet } & Zero pressure \\
\hline \multirow{2}{*}{$\begin{array}{l}\text { Material- } \\
\text { Fluid }\end{array}$} & \multirow{2}{*}{ air } & Density $\left[\mathrm{kg} / \mathrm{m}^{3}\right]$ & 1.225 \\
\hline & & Viscosity [Pa.s] & $1.789 \mathrm{e}-5$ \\
\hline
\end{tabular}

After the simulation have been done, all the data that generate from simulation will be record. Calculation will be made for two and three direction cases. The equation that will be used as follow :

$V s / e=V s / c+V c / e$

The parameter used in this formula is relative velocity of the sensor, $V s / e$. Vs/e is the velocity of the sensor relative to the earth with respect to velocity sensor to the car, $V s / c$ and velocity of the speedometer to earth, Vsc/e [9]. Hence, verification of the data can be done by comparison of simulation and calculation method.

\section{Results and Discussion}

\subsection{Simulation Result in One Direction}

For the simulation result in one direction, Figure 3 indicated that the airflow only fully cover the 3 out of 16 entrance model structure when one direction of airflow velocity is applied. This can be proved by highlighted red region in pressure contour at 4.049Pa for low velocity region. However, the structure material 
still can within the elastic region which is below than 70MPa for polylactide (PLA) material [10].

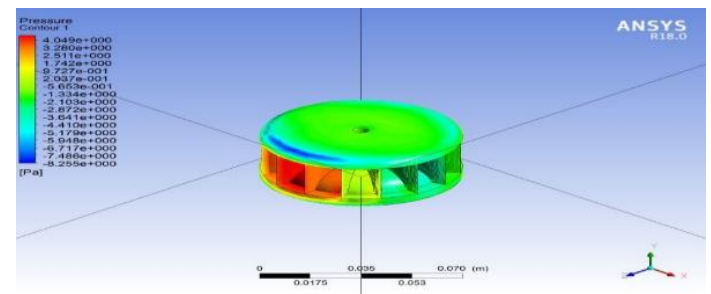

Fig 3: Pressure contour at $1.5 \mathrm{~m} / \mathrm{s}$

In other hand, the simulation in Figure 4 reveal that, uneven flow of stremline had occur inside the model structure starting from the entrance. The streamline flow also not fully enter into the entrance structure which is will be effect the sensitivity detection of airflow movement. Improper design in term of aerodynamic flow inside the structure model is factor for this problem. The streamline of velocity should be smooth starting from the entrance to the exit hole of the model structure.

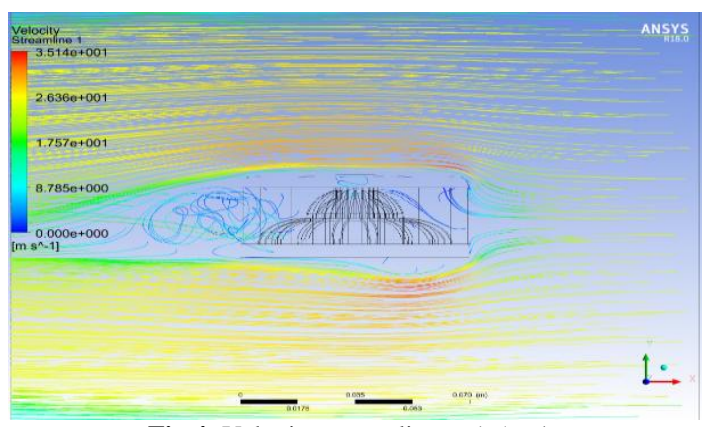

Fig 4: Velocity streamline at $1.5 \mathrm{~m} / \mathrm{s}$

\subsection{Simulation Result in Two Directions and Three Directions}

For this case, simulation have been change into two dimentional view to find total resultant of velocity at particular plane that acting on the structure. For two direction of airflow analysis, two value of velocity is set at $\mathrm{x}$-direction and - $\mathrm{x}$-direction at the enclosure. Table 4 presents that comparision data between calculation and simulation result. For the velocity 1 , value is used starting from $2.0 \mathrm{~ms}^{-1}$ and gradually increase until $4.5 \mathrm{~m} \mathrm{~s}-1$. For the velocity 2 , fixed variable is set at $8.0 \mathrm{~m} \mathrm{~s}-1$. As shown in Table 4, simulation result have found that slightly lower compared to calculation result for all attempt. This is because, uneven flow inside the model structure that had been mention before is the main reason which affects the simulation result. Percentage error are also shows in this Table which stated that there are diferrent value between calculation and simulation result in the range of $3.65 \%-6.62 \%$.

Table 4: Calculation and simulation result for two directions

\begin{tabular}{|c|c|c|c|c|}
\hline $\begin{array}{c}\text { Velocity 1 } \\
\left(\mathbf{m ~ s}^{-1}\right)\end{array}$ & $\begin{array}{c}\text { Velocity 2 } \\
\left(\mathbf{m ~ s}^{-1}\right)\end{array}$ & $\begin{array}{c}\text { Calculation } \\
\text { Result } \\
\left(\mathbf{m ~ s}^{-1}\right)\end{array}$ & $\begin{array}{c}\text { Simulation } \\
\text { Result } \\
\left(\mathbf{m ~ s}^{-1}\right)\end{array}$ & $\begin{array}{c}\text { Error } \\
(\%)\end{array}$ \\
\hline $\mathbf{2 . 0 0}$ & $\mathbf{8 . 0}$ & 6.0 & 5.603 & 6.62 \\
\hline $\mathbf{2 . 5 0}$ & $\mathbf{8 . 0}$ & 5.5 & 5.299 & 3.65 \\
\hline $\mathbf{3 . 5 0}$ & $\mathbf{8 . 0}$ & 5.0 & 4.744 & 5.12 \\
\hline $\mathbf{4 . 0 0}$ & $\mathbf{8 . 0}$ & 4.5 & 4.328 & 3.82 \\
\hline $\mathbf{4 . 5 0}$ & $\mathbf{8 . 0}$ & 4.0 & 3.764 & 5.90 \\
\hline
\end{tabular}

Moreover, another velocity is added at z-direction for three direction analysis. Calculation and simulation result for three direction analysis is shown in Table 5 . For the velocity 1 , value is used starting from $2.0 \mathrm{~m} \mathrm{~s}^{-1}$ and gradually increase until $4.5 \mathrm{~m}$ $\mathrm{s}-1$. For the velocity 2 and velocity 3 , fixed variable is set at $8.0 \mathrm{~m}$ $\mathrm{s}^{-1}$ and $2.0 \mathrm{~m} \mathrm{~s}^{-1}$ respectively. Table 5 shows that, there are also have different value between calculation and simulation result for 3 direction analysis. Percentage error are also shows in this Table which stated that there are diferrent value between calculation and simulation result in the range of $4.4 \%-7.8 \%$.

Data from the Table 5 can be compared with the data in Table 4 which shows that, there are similar value in calculation result between these two cases. This is because, velocity magnitude 3 in three direction case is set at z-direction should be approximately zero at $\mathrm{x}$-axis, and have same result with the two direction case. However, what is interesting in this data is that, Table 5 shows the simulation result for three direction case have slightly diferrence compared to simulation result for two direction case in Table 4 . This is because, some of velocity magnitude 3 was hit the wall of structure entrance and change it direction which is affect the total resultant of velocity of the model structure in three direction case. Hence, the simulation result for relative velocity shows the diferrence in these two cases.

Table 5: Calculation and simulation result for three directions

\begin{tabular}{|c|c|c|c|c|c|}
\hline $\begin{array}{c}\text { Velocity } \\
\mathbf{1} \\
\left(\mathbf{m ~ s}^{-\mathbf{1}}\right)\end{array}$ & $\begin{array}{c}\text { Velocity } \\
\mathbf{2} \\
\left(\mathbf{m ~ s}^{-\mathbf{1}}\right)\end{array}$ & $\begin{array}{c}\text { Velocity } \\
\mathbf{3} \\
\left(\mathbf{m ~ s}^{-\mathbf{1}}\right)\end{array}$ & $\begin{array}{c}\text { Calculation } \\
\text { Result } \\
\left(\mathbf{m ~ s}^{-\mathbf{1}}\right)\end{array}$ & $\begin{array}{c}\text { Simulation } \\
\text { Result } \\
\left(\mathbf{m ~ s}^{-1}\right)\end{array}$ & $\begin{array}{c}\text { Error } \\
(\boldsymbol{\%})\end{array}$ \\
\hline $\mathbf{2 . 0}$ & $\mathbf{8 . 0}$ & $\mathbf{2 . 0}$ & 6.00 & 5.533 & 7.78 \\
\hline $\mathbf{2 . 5}$ & $\mathbf{8 . 0}$ & $\mathbf{2 . 0}$ & 5.50 & 5.258 & 4.40 \\
\hline $\mathbf{3 . 5}$ & $\mathbf{8 . 0}$ & $\mathbf{2 . 0}$ & 5.00 & 4.703 & 5.94 \\
\hline $\mathbf{4 . 0}$ & $\mathbf{8 . 0}$ & $\mathbf{2 . 0}$ & 4.50 & 4.242 & 5.73 \\
\hline $\mathbf{4 . 5}$ & $\mathbf{8 . 0}$ & $\mathbf{2 . 0}$ & 4.00 & 3.717 & 7.07 \\
\hline
\end{tabular}

\section{Conclusion}

The current paper was designed to determine the effect of single and multi-flow direction of air flow velocity towards airflow sensor. In this paper, simulation of airflow in single direction was designed to evaluate and characterise the small change of air flow acting on the model structure. Based on the result concluded, the model sensorable to detect the airflow accurately in 3 out of 16 entrance model structure when one direction of airflow velocity is applied. The percentage difference between the simulation and calculation was less that $10 \%$ which indicates that the airflow sensor able to achieve the accuracy of the written objective. Hence, in recommendation for future works is to integrate more significant parameter which covers the environmental area or that may effects the accuaracy of the airflow sensor. The characterization data and result that have been obtained from the simulation and calculation can be use as guidance point during actual experimental stage to define the mapping for the airflow movement and bending structure behaviour.

The on-going stage is development of the prototype based on the optimization of the analysed data. First approach that had been used is by rapid prototyping to match the material set in the analysis. As shown in Figure 5, the prototype structured was printed by using 3D printing with PLA material. The sensor mechanicsm will be integrated inside the structure to capture the value of the bending moment from the incoming airflow movement. The result will be elaborated more in the future paper.

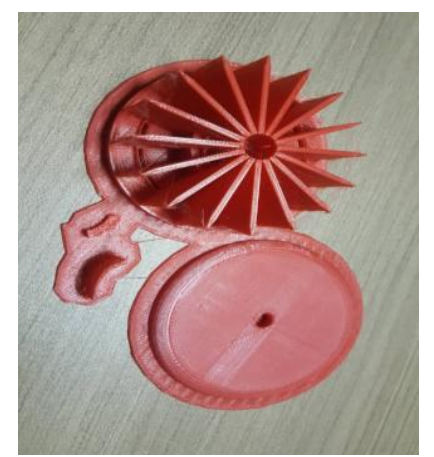

Fig 5: Prototype structure of the airflow sensor 


\section{Acknowledgement}

This research was financially supported by the Geran Inisiatif Penyelidikan (600-IRMI/MyRA 5/3/GIP (012/2017), Universiti Teknologi MARA, Malaysia.

\section{References}

[1] M. D. bin Amari, S. C. Abdullah and M. A. Ayub (2018), "Concept development stage of hyper sensitivity dynamic airflow sensor in low velocity region," $20183 \mathrm{rd}$ International Conference on Control and Robotics Engineering (ICCRE), Nagoya, pp. 147-150.

[2] M. D. bin Amari and S. C. Abdullah (2017), "A Model for Hypersensitive Airflow Sensor Concept", Journal of Mechanical Engineering, Vol. SI 4(3), 163-174, 2017.

[3] T. R. Ohnstein,R.G. Johnson, R. E. Higashi, D. W. Burns, J. O Holmen, E. A Satren, el al.,editor(1990). "Environmentally rugged, wide dynamic range microstructure airflow sensor" Technical Digest, Solid-State Sensor and Actuator Workshop.

[4] M. M. Ji L. Piao and B.H.Li(2011),"Three-dimentional modeling and simulation for airflow inclination sensor". Advance material Research, 640-645.

[5] N. Svedin, E. Kälvesten, and G. Stemme (2003), "A lift force sensor with integrated hot-chips for wide range flow measurements," Sensors Actuators, A Phys., vol. 109, no. 1-2, pp. 120-130.

[6] A. A Bent, N.W.Hagood and J. P Rodgers, (2003) "Anisotropic actuation with piezoelectric fiber composites" Journal of Intelligent Material Systems and Structures,6, 338-349.

[7] H. Sato, Y, Shimojo and T. Sekiya, "Development of smart board using metal core piezoelectric complex fibres" $12^{\text {th }}$ International Conference on Transducers.

[8] M. J. Zulhaidi, S. Rohayu, W. S. Voon, and S. Ahmad Farhan, (2009), Weather as a road safety hazard in Malaysia-an overview.

[9] L.Xinbo, et al. (2016),"Wind speed and direction measurement based on are ultrasonic sensor arry signal processing algorithm"ISA Transactions 65,437-445.

[10] J. Torres, J. Cotelo, J. Karl, and A. P. Gordon (2015) "Mechanical property optimization of FDM PLA in shear with multiple objectives," Jom, vol. 67, no. 5, pp. 1183-1190 